\title{
Understanding Transport-Related Social Exclusion Through the Lens of Capabilities Approach
}

\author{
Gregório $\mathrm{Luz}^{1,2,{ }^{*}}$ and Licinio Portugal ${ }^{1}$ \\ ${ }^{1}$ Transport Engineering Program, Alberto Luiz Coimbra Institute for Graduate Studies and \\ Research in Engineering (COPPE), Federal University of Rio de Janeiro (UFRJ), Rio de Janeiro, \\ Brazil, \\ ${ }^{2}$ Center for the Study of the Politics and Economics of the Public Sector, Getulio Vargas \\ Foundation (CEPESP/FGV), São Paulo, Brazil
}

Preprint of the paper published in Transport Reviews at 17 Nov 2021

https://doi.org/10.1080/01441647.2021.2005183

Correspondence:

gregorioluz@pet.coppe.ufrj.br

https://orcid.org/0000-0002-6386-6587 


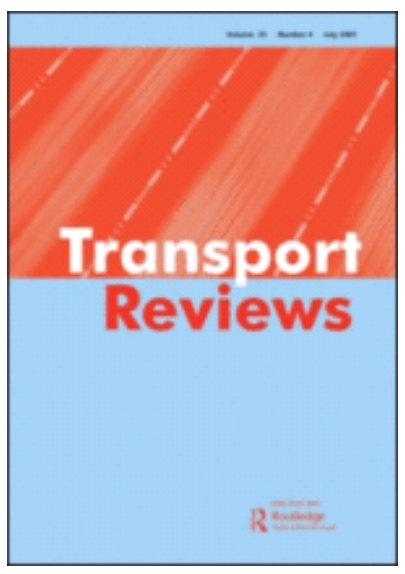

\section{Understanding Transport-Related Social Exclusion Through the Lens of Capabilities Approach}

\begin{tabular}{|r|l|}
\hline Journal: & Transport Reviews: A Transnational Transdisciplinary Journal \\
\hline Manuscript ID & TTRV-2020-0336.R3 \\
\hline Manuscript Type: & Research Article \\
\hline Keywords: & $\begin{array}{l}\text { transport-related social exclusion, accessibility poverty, capabilities } \\
\text { approach, transport disadvantage, accessibility as a human capability, } \\
\text { accessibility disadvantage, accessibility, accessibility measures, } \\
\text { accessibility indicators, equity }\end{array}$ \\
\hline \multicolumn{2}{|l}{} \\
\hline
\end{tabular}

\section{SCHOLARONE Manuscripts}




\title{
Understanding Transport-Related Social Exclusion Through the Lens of Capabilities Approach
}

\begin{abstract}
The paper builds on the TRSE literature and investigates how the insights provided by the Capability Approach can help to inform inclusive transport planning. To address the literature lack of conceptual clarity, we provided a framework that considers how individuals may be prevented from travelling and accessing valued opportunities and how this may lead to TRSE. Ten different dimensions of TRSE that individuals may experience are suggested. Although some dimensions were already proposed in past work, we contributed to this framework by expanding their scope and proposing a new dimension. The paper concludes that policies aimed at reducing TRSE should be concerned with increasing the capabilities of those in accessibility poverty to a sufficient level that enables individuals' participation in key opportunities of the society. We identified that not every accessibility measure is suitable for assessing TRSE, and the selection of measures must pay attention to their alignment with the idea of accessibility as a human capability. We recommend that conducting an aggregated analysis may be helpful to identify a suitable accessibility measure and to identify regions at risk of TRSE; however, to have a deep understanding of an individual's TRSE risk factors, a bottom-up analysis is necessary.
\end{abstract}

Keywords: transport-related social exclusion; accessibility poverty; capabilities approach; transport disadvantage; accessibility disadvantage; accessibility as a human capability

\section{Introduction}

Social exclusion has significant economic and social costs associated with renouncing the contribution of individuals and groups that cannot access critical opportunities in society, such as education, employment, and health (United Nations, 2016). Also, social exclusion presents political risks, as it reflects and sustains social tensions and is at the origin of many violent conflicts (United Nations, 2016). Individuals who are socially excluded are also those who inhabit the areas that are more vulnerable to natural hazards and disasters 
and are disproportionately harmed by them. Exclusion makes society not only less cohesive but also less safe (United Nations, 2016).

Over the last two decades, the number of studies concerned with the nexus between transport and social inclusion has increased dramatically. The report published by the Social Exclusion Unit (Social Exclusion Unit, 2003) was the watershed that put the theme of social exclusion on the transport policy agenda. Since then, several conceptual and review studies have been done addressing a variety of issues related to the transport-related social exclusion (TRSE) topic, such as the role of ICT in reducing social exclusion (Durand et al., 2021; Kenyon et al., 2002; Lucas, 2019); the relationship between mobility, accessibility, and social exclusion (Cass et al., 2005; Preston \& Rajé, 2007); the centrality of accessibility in the social inclusion and equity agenda (Farrington \& Farrington, 2005; Farrington, 2007; van Wee \& Geurs, 2011); the link between transport and well-being (Adeel et al., 2016; Currie et al., 2010; Ma et al., 2018; Oviedo \& Sabogal, 2020); the relationship between social capital, transport and social inclusion (Gray et al., 2006; Schwanen et al., 2015) the synergy between social exclusion and environmental justice in transport policies (Lucas, 2006); how TRSE concepts and definitions have been translated into policy and practice (Lucas, 2012); transport appraisal methods and social exclusion (Lucas et al., 2016; van Wee \& Geurs, 2011), and measures of TRSE (Kamruzzaman et al., 2016; Pyrialakou et al., 2016). This large amount of works originated a growing lack of conceptual clarity about what TRSE and its related terms actually mean (Arranz-López et al., 2019).

Many have argued that the Capabilities Approach is the most appropriate fairness approach to express complex concepts (Bantis \& Haworth, 2020; Hananel \& Berechman, 2016; Martens, 2016b; Pereira et al., 2017) and, therefore, to consider the broad diversity of individuals and how it interacts with transport and land use resources to affect people's 
opportunities (Vecchio \& Martens, 2021). The number of studies interested in the application of Amartya Sen's Capabilities Approach (CA) in transport research also has increased recently (Beyazit, 2011; Cao \& Hickman, 2019; Hananel \& Berechman, 2016; Mella-Lira, 2017; Martens, 2016a; Pereira et al., 2017; Ryan et al., 2015, 2019; Vecchio \& Martens, 2021) and the many distinct definitions of the related concepts generated varied operational applications (Vecchio \& Martens, 2021).

This paper builds on the TRSE literature and investigates how the insights provided by the Capability Approach can help to inform inclusive transport planning. We provide a broad and detailed critique overview of TRSE literature and bring together many of its concepts to tackle the current lack of clarity. We add to the state-of-the-art by providing a framework that considers how individuals may be prevented from travelling and accessing valued opportunities and how this may lead to each form of TRSE. Based on the past work, we suggest ten different dimensions of TRSE that individuals may experience. Although some categories were already proposed in past work, we contribute to this framework by expanding their scope and proposing a new dimension. We also identified that not every accessibility measure is suitable for assessing TRSE and recommend a strategy to identify a suitable one.

This paper is structured as follows. Section 2 presents the research design. Section 3 and 4 define social exclusion, TRSE, and related terms (transport disadvantage, transport poverty, accessibility disadvantage and accessibility poverty). Section 5 connects the TRSE theory to the Capabilities Approach. Section 6 presents a conceptual framework about how accessibility as human capability components may interact to generate ten different forms of TRSE. Section 7 discusses the challenges of inclusive accessibility planning and makes recommendations to select an appropriate accessibility measure to assess TRSE. Lastly, Section 8 presents a discussion about some of the 
implications for TRSE research and policymaking and provides recommendations for future research.

\section{Research Design}

The materials reviewed in this article are primarily from articles published in journals until July 2021. The search strategy for the selection of relevant literature to this article's development was based on published papers in English with the following quotes - ("transport*" AND "social exclusion"), "transport-related social exclusion", and "transport disadvantage" - in the publication title, abstracts, and keywords for all time. The Scopus database was used to obtain relevant full-text literature pieces. After filtering by only papers published in journals, the search provided a total of 433 papers. These articles were then submitted to a "Citation" analysis in the VosViewer software to identify the literature's core articles on TRSE. The "Citation" analysis determines the papers' relatedness based on the number of times they cite each other. We filtered the 433 papers with at least ten links with the others in the group. To mitigate a selection bias of older documents, we use a lower threshold of eight links for articles published in the last five years and five links thresholds for papers published after 2016. After filtering the papers, 118 articles were left. These publications were read and analysed in more detail to examine whether the concepts, methods, and results revealed theoretical understandings related to TRSE. After a careful examination, 58 out of the 118 articles were included in the final literature selection. After that, we used a forward and backward snowball method to complement the systematic literature review. We identified 50 additional research pieces, including books, book chapters, papers, and reports. The final literature reviewed thoroughly in this paper consists of 108 pieces of research. 


\section{Defining Social Exclusion}

Social exclusion is a broad and complex concept that goes beyond economic and material issues (Church et al., 2000; Hodgson \& Turner, 2003; Schwanen et al., 2015; Stanley \& Vella-Brodrick, 2009). Burchardt et al. (1999, p. 229) suggest that an individual is socially excluded if (a) he or she is geographically resident in a society but (b) for reasons beyond his or her control he or she cannot participate in the normal activities of citizens in that society and (c) he or she would like to so participate. Non-participation in society is related to the deprivation process, which is characterised as the lack of attributes that contribute to some kind of suffering or relative disadvantage (Higgs \& White, 2000). These attributes include, but are not limited to, income and material resources. This distinction between poverty and social exclusion allows us to acknowledge that poverty does not necessarily lead to exclusion; and that an individual can be excluded without being poor (Kenyon et al., 2002; Preston \& Rajé, 2007). Social inclusion, in turn, refers to "the process of improving the terms of participation in society for people who are disadvantaged" (United Nations, 2016, p. 20) and is both a process and a goal to be achieved. Promoting social inclusion requires tackling social exclusion by removing barriers to participation in society and actively "bringing people in", taking steps to facilitate such participation. (United Nations, 2016)

Social exclusion focuses on the processes of unequal access to participation in society (Kenyon et al., 2002) and is a multidimensional, dynamic and relative process. It changes over time, and individuals cannot be considered excluded in isolation, it is necessary to take into account a broader context of other individuals' activities (Burchardt et al., 1999; Hodgson \& Turner, 2003; Schwanen et al., 2015; Stanley \& Vella-Brodrick, 2009). An important question related to social exclusion is whether the low / nonparticipation in society is the result of voluntary choices or not (van Wee \& Geurs, 2011). 
Burchardt et al. (1999) point out that individuals are not excluded by their own choice. An individual is socially excluded if, for reasons beyond his control, he would like and cannot participate. Thus, the powerless and denial of choice inherent in social exclusion discourse prevents the extension of the concept to those who self-exclude (Kenyon et al., 2002, p. 209).

The exclusion experienced by individuals results from a unique interaction between the dimensions and characteristics of exclusion specific to that individual's circumstances. These dimensions of exclusion are cumulative and reinforce each other. Social exclusion is also somewhat circular, with social exclusion being both a cause of lack of personal opportunities and an outcome or a reason for lack of personal opportunities (Stanley \& Vella-Brodrick, 2009). The main result of social exclusion is the lack of participation, and deprivation indicators, such as income, low education, little political power, are only causes or risk factors for social exclusion. None of these indicators would be considered social exclusion if the individual, even with all the adverse conditions, could participate in the different dimensions that activities can take (Burchardt et al., 1999).

\section{Nexus of Social Exclusion and Transport}

Several concepts are used to refer to the nexus between social exclusion and transport. There is no consensus about the most commonly used terms, including transport disadvantage, transport poverty, accessibility disadvantage, and accessibility poverty. In this sense, it is essential to define them and clarify how they relate to each other before going deeper into the transport-related social exclusion concept.

Transport disadvantage is defined by some authors as the difficulties to travel when needed (Currie et al., 2010; Denmark, 1998). Other authors broaden the 
understanding of the transport disadvantage to the problems in accessing opportunities because of difficulties of transport, that is, difficulties in potential mobility - defined as a person's ability to move through space (Kamruzzaman et al., 2016; Marquet et al., 2017; Martens, 2015; Oviedo \& Sabogal, 2020; Pyrialakou et al., 2016; Vecchio \& Martens, 2021; Xiao et al., 2018). More "indirect" forms of transportation disadvantage, such as the relative lack of power to affect the formulation and governance of transportation policies (Denmark, 1998; Hodgson \& Turner, 2003), high exposure to negative transport externalities such as traffic accidents, poor air quality, or excessive noise, is also mentioned in the literature (Schwanen et al., 2015).

Although similar to the transport disadvantage concept, transport poverty is used to refer to a lack of resources related to transport that hinders an individual's potential mobility and, therefore, its ability to access opportunities (Groth, 2019; Jeekel \& Martens, 2017; Martens, 2016a). It means that a person who experiences transport poverty cannot access key opportunities because he/she lacks access to adequate means of transport. Other definitions of transport poverty include the combined effect of transport disadvantage with social disadvantage (e.g., unemployment, low income, etc.), resulting in adverse outcomes like lengthy commutes and inaccessibility (Lucas, 2012). Also, the literature uses the transport poverty term to refer to the affordability of transport costs, and it is employed alongside other notions such as "transport affordability", "forced car ownership", and "car-related economic stress" (Mattioli et al., 2018).

The terms accessibility poverty and accessibility disadvantage are centred on a more comprehensive interpretation of the notion of resources than the transport poverty and transport disadvantage (Jeekel \& Martens, 2017). Accessibility poverty refers to a situation where an individual's level of accessibility is insufficient to provide access to key opportunities in a society, such as health care, employment, education, or social 
support networks (Lucas, 2012; Martens \& Bastiaanssen, 2019). Accessibility disadvantage, in turn, refers to the difficulties of accessing normal opportunities in a society when needed. Difficulties or inability to access activities may be due to transport problems but may also be related to individual characteristics and land use patterns (e.g., when a person has a high level of potential mobility but lives in a remote location without activities).

Kenyon et al. (2002, pp. 210-211), in their seminal paper, defined transportrelated social Exclusion (TRSE) as:

"The process by which people are prevented from participating in the economic, political and social life of the community because of reduced accessibility to opportunities, services and social networks, due in whole or in part to insufficient mobility in a society and environment built around the assumption of high mobility."

From the TRSE definition of Kenyon et al. (2002), it is possible to establish some relationships between the TRSE notion and the concepts previously presented. First, TRSE is primarily about the lack of possibilities for participation in the community (society) and not necessarily about the resources available to a person (Jeekel \& Martens, 2017). Second, TRSE occurs when accessibility disadvantage reaches a critical level (accessibility poverty), and systematic problems of access to opportunities prevent participation in society. Third, the problems in accessing opportunities may be due in whole or in part to difficulties in travelling (transport disadvantage) or insufficient (potential) mobility (transport poverty). Fourth, persons facing accessibility poverty are at risk of transport-related social exclusion (Jeekel \& Martens, 2017).

One may think that improving access to opportunities, and hence accessibility, means improving potential mobility, but this is likely to be a limited solution, not fully 
viable or sustainable (Bantis \& Haworth, 2020; Bocarejo \& Oviedo, 2012; Farrington \& Farrington, 2005; Gray et al., 2006; Kenyon et al., 2002; Lucas, 2006). Excessive mobility by private and unsustainable modes can increase social exclusion by contributing to the decline in public transport and widening the mobility gap in society (Denmark, 1998; 2016a; Pereira et al., 2017). Although transport planning based on increasing the flow speed has improved accessibility for many who uses private cars, it has neglected the condition of people who are poorly served by the current public transportation systems, with negative consequences for their access to destinations and their ability to participate in society fully (Lucas, 2012; Martens, 2016a; Pucci et al., 2019; van Wee \& Geurs, 2011; Vecchio \& Martens, 2021).

In this sense, the notion of "mobility rights" is less powerful in articulating social inclusion than the notion of "accessibility rights" since mobility is but one (albeit critical) way of achieving accessibility (Farrington, 2007; Pucci et al., 2019). The discourse of "accessibility rights" does not conflict with the mobilities discourse because it acknowledges the "significant role that mobility plays, and will continue to play, in achieving the spectrum of people's needs for reaching and participating in activities, services, and opportunities" (Farrington, 2007, p. 327). The accessibility notion was introduced in the late 1950s by Hansen (1959). However, its link with social exclusion emerged with UK policymakers in the early 2000s. The iconic document "Making the Connections: Transport and Social Exclusion", launched by the Social Exclusion Unit (2003), brought a new narrative to accessibility and changed the discourse from "potential of opportunities for interaction" to the ability of people to reach and take part in activities normal for that society (Farrington \& Farrington, 2005; Farrington, 2007). 


\section{Framing Accessibility into Capability Approach}

The interest in applying Amartya Sen's Capabilities Approach (CA) in transport research has increased recently (Bantis \& Haworth, 2020; Beyazit, 2011; Cao \& Hickman, 2019; Hananel \& Berechman, 2016; Mella-Lira, 2017; Martens, 2016a; Pereira et al., 2017; Vecchio \& Martens, 2021). When compared to other transportation fairness approaches, the Capabilities Approach is better suited to account for the individuals `wide diversity, considering not only how transport and land use resources are distributed and interact with each other, but also how these affect people's opportunities differently depending on their characteristics, aspirations, and choices (Vecchio \& Martens, 2021). The CA provides flexibility to express complex concepts (Bantis \& Haworth, 2020; Hananel \& Berechman, 2016; Martens, 2016a; Pereira et al., 2017), being helpful to articulate a broader notion of accessibility that incorporates individuals` characteristics.

Individual freedom of choice and human agency are at the heart of the CA's concerns (Nussbaum \& Sen, 1993). CA states that a person's well-being should be based on its real opportunities to do and be what they reason to value (Sen, 1985). Contrary to Rawl's egalitarian approach (Rawls, 2009), where the emphasis is on the primary goods, Sen argues that commodities or wealth people have provide only limited or indirect information about how well life is going (Sen, 2009). CA focuses on the well-being that individuals achieve because of the things they actually do and be, but also the things they could potentially do and be. CA's four notions are central in analysing this well-being: resources, the conversion function, functionings, and capabilities.

- Resources are the commodities and intangible goods available to a person to pursue the life they value. It depends on a person's characteristics, background, and social-spatial context. Resources are the "means to achievement" (Sen, 1995). 
- The conversion function determines the possibility of converting resources into freedoms and conveying the personal, social, and environmental conditions that form its life experience (Sen, 1995).

- Functionings are the various things a person may value 'being and doing,' such as being well-nourished, having shelter, and participating in political decisions (Sen, 1995, 2009).

- Capabilities refer to the set of functionings (the combinations of beings and doings) that a person has effective access to. Each capability is "whatever [people] are able to do and be in a variety of areas of life" (Nussbaum \& Sen, 1993, p.2). In other words, capabilities are the set of opportunities and freedoms available for individuals to choose and to act (Nussbaum, 2011; Sen, 2009).

Transport research based on CA is diverse in its theoretical conceptualisations, reflected in the various understanding of the CA notions and, consequently, different operational implications.

Although mobility is not addressed directly by the main theorisations of CA (Vecchio \& Martens, 2021), some transport researchers consider it a capability (Beyazit, 2011; Hananel \& Berechman, 2016; Ryan et al., 2019). This school of thought views mobility as "being physically, socially and financially able to move from one place to another and interact within society or with different societies" (Beyazit, 2011, p. 123), an understanding that is close to the concepts of motility (Flamm \& Kaufmann, 2006; Kaufmann, 2002) - defined as "the way in which an actor appropriates the field of possible action in the area of mobility, and uses it to develop personal projects" (Kaufmann, 2002, p. 3) - and potential mobility. 
A different conceptualisation of CA in transport research is accessibility as a human capability. This line of thought defines accessibility similarly to the accessibility narrative brought about by TRSE studies: "persons` possibility in engaging in a variety of out-of-home activities" (Martens, 2016a, p. 137). This definition comprises the idea of a "person's ability to move through space" but goes further considering a person's ability to translate resources into activity participation (Martens et al., 2012; Vecchio \& Martens, 2021). Since we are concerned with ensuring not just that people move through space but that they reach and participate in activities to be socially included, the idea of accessibility as a capability makes more sense than mobility as a capability to inform social inclusion. The notion of accessibility as a human capability incorporates the land-use component and considers how it interacts with the transport systems components to enhances people's capabilities (Pereira et al., 2017). While accessibility captures the people's possibilities to participate in valued activities, mobility is a means (Bantis \& Haworth, 2020; Cao \& Hickman, 2019; Oviedo \& Guzman, 2020; Ryan et al., 2015), but it is not the only one, some accessibility may be acquired virtually.

In the accessibility as a human capability approach, resources comprise a wide variety of tangible and immaterial means, particularly related to transport systems and land use, that affect a person's mobility and accessibility directly or indirectly (Vecchio $\&$ Martens, 2021). The value of these resources will depend on the social, environmental and economic conditions and individuals' ability (conversion function) to convert them into functionings they value. Functionings are what the individuals actually do and how, reflected by their travel behaviour and activities participation pattern (Hickman et al., 2017). The individual's capabilities is its accessibility, represented by the freedom to choose from different potential functionings (ways of moving around and possibilities of activity participation) (Hickman et al., 2017). The individual's well-being, in turn, is 
shaped by his capabilities (accessibility) and their functionings (travel and activity participation) (Vecchio \& Martens, 2021).

The accessibility as a human capability works as a reinforcing cycle. While individuals`ability to convert resources into actual participation (functionings) influences their well-being, the functionings realised, and well-being achieved from them contribute to improving their conversion function and, consequently, their capabilities (Figure 1). For example, individuals that access and participate in higher education (functionings) can get qualified (conversion function) to participate in an employment activity close to their residence that they could not before (capability). Alternatively, elderly individuals who access a park close to their home for exercise (functioning) may have better health (well-being) and face fewer problems when boarding public transport vehicles (conversion function).

Figure 1. Accessibility as a Human Capability

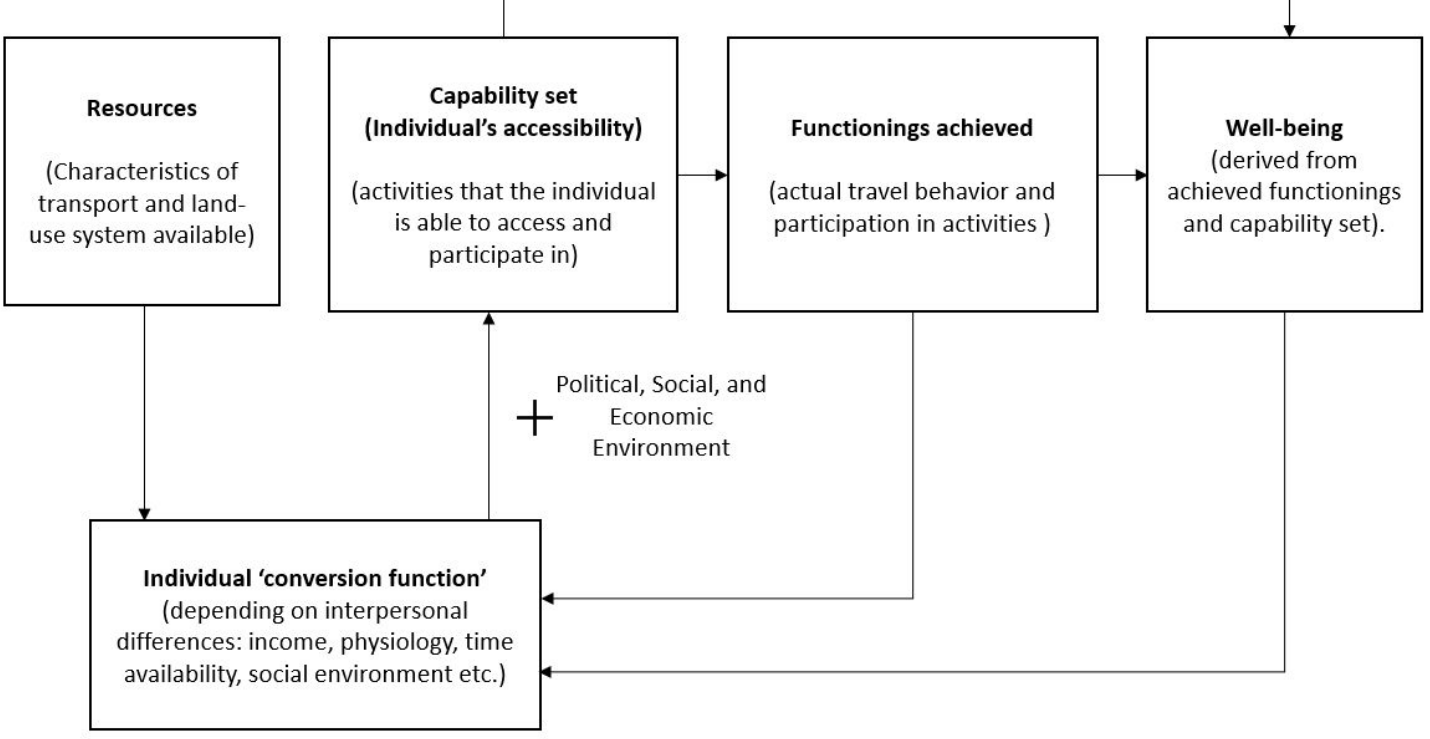

Source: Authors

Transport planning approaches aimed to mitigate social exclusion often fetishise resources as the personification of advantage (Nussbaum, 2011; Pereira et al., 2017). 
These approaches ignore how people's ability to convert land-use and transport-related resources into capability and well-being is affected by contingencies, such as personal characteristics, physical environment, and cultural norms (Pereira et al., 2017).

The CA is particularly interested in promoting minimum levels of capability, which is crucial for equality of opportunities and freedom to do things vital for survival and later development (Nussbaum, 2011; Pereira et al., 2017). This idea shares sufficientarian concerns discussed by some authors (Lucas et al., 2016; Martens, 2016a; van Wee \& Geurs, 2011; Vecchio \& Martens, 2021), which presupposes that everyone should be well off up to a given minimum threshold sufficient to meet their basic needs and ensure their well-being (Lucas et al., 2016). Weak sufficientarianism suggests that improvements for people below the threshold are preferred, while strong sufficientarianism implies that transport policy should be based on preventing accessibility poverty first and foremost (Meyer \& Roser, 2009; van der Veen et al., 2020). Public policies aimed to reduce TRSE must be concerned not only with providing a minimum level of access to essential activities (sufficient functionings) to individuals but also providing a reasonable level of freedom to them choose what they want "to do and be" (sufficient capabilities) (Nahmias-Biran et al., 2017; Vecchio \& Martens, 2021).

\section{Accessibility as a Human Capability and the TRSE dimensions}

The idea of accessibility as a human capability has two separable but interacting components that we named spatial resources and individual's conversion function. These components are derived from traditional accessibility components: transportation, land use, temporal, individual, and cognitive (Geurs \& van Wee, 2004; Lucas, 2012). The spatial resources component refers to the more macroscopic view of accessibility. It comprises two subcomponents: land-use patterns and transport systems and their 
respective temporal restrictions. The individual's utilisation function component of accessibility refers to a person's perceptions and abilities to convert spatial resources into access to activities, given their interaction with external factors, the social, economic, and political environment. It incorporates the individual's temporal and cognitive restrictions.

The interaction of spatial resources with the individual's conversion function and the external environment may expand or limit the individual's capabilities. When the limitation of individuals' capabilities reaches a critical level (accessibility poverty), and systematic problems in accessing opportunities prevent their participation in the normal activities of citizens in their society, they become transport-related socially excluded. Individuals may face different forms of TRSE depending on the barriers to participation that emerged in the interaction process between the spatial resources, individual conversion function, and external environment (Figure 2).

Several studies have proposed dimensions of TRSE. The first study in this sense was that of Church et al. (2000), who proposed seven dimensions: physical exclusion, exclusion, geographical exclusion, exclusion from facilities, economic exclusion, timebased exclusion, fear-based exclusion, and space exclusion. Hine \& Mitchell (2001) proposed five dimensions: Physical, Economic, Temporal, Spatial, and Psychological. The spatial dimension of Hine \& Mitchell (2001) corresponds to the geographical and space-related dimensions of Church et al. (2000), and the psychological dimension relates to fear-based exclusion. Cass et al. (2005) identified four dimensions of access related to social exclusion: Economic, Physical, Temporal, and Organisational. The first three dimensions of Cass et al. (2005) are quite similar to those of Church et al. (2000) and Hine \& Mitchell (2001). The fourth organisational dimension refers to the ability to use the different modes of transport in terms of suitable and convenient timetables, network structure, the quality of the experience, frequency, reliability, and punctuality. Yigitcanlar 
et al. (2019), in turn, considered six dimensions, five that are pretty similar to those presented by other authors, and the informational dimension, which refers to the availability of information for the use of public transport. Finally, Benevenuto \& Caulfield (2019) proposed eight dimensions of social exclusion, the seven already proposed by Church et al. (2000) plus social position-based exclusion.

Based on their work, we suggest ten different dimensions of TRSE to describe as accurately as possible the different types of TRSE experienced by individuals. Although most categories received the same name as in the cited works, we contribute to this framework by expanding many of their scopes. Also, we propose a new category that was not mentioned in past work, the digital divide exclusion.

We propose a framework that connects the idea of accessibility as human capability and its related terms with the ten TRSE dimensions (Figure 2). This framework, together with the one presented in Figure 1, allows consideration of how each individual may be prevented from travelling and accessing valued opportunities and how this may lead to each form of TRSE. In Figure 2, the interaction between land-use and transport systems defines the spatial resources notion. The interaction between transport resources, individual's conversion function, and the political, social, and economic environment represent the concepts of potential mobility, mobility as a capability, and motility. If we add the land use component to the latter, we obtain accessibility as a human capability. Depending on how this interaction process occurs and the shortcomings in these building blocks, TRSE may take different forms. The descriptions of the ten TRSE dimensions are presented below. It is important to note that these ten dimensions are interrelated and may overlap in many aspects.

Figure 2. Relationship between accessibility as human capability components and TRSE dimensions 


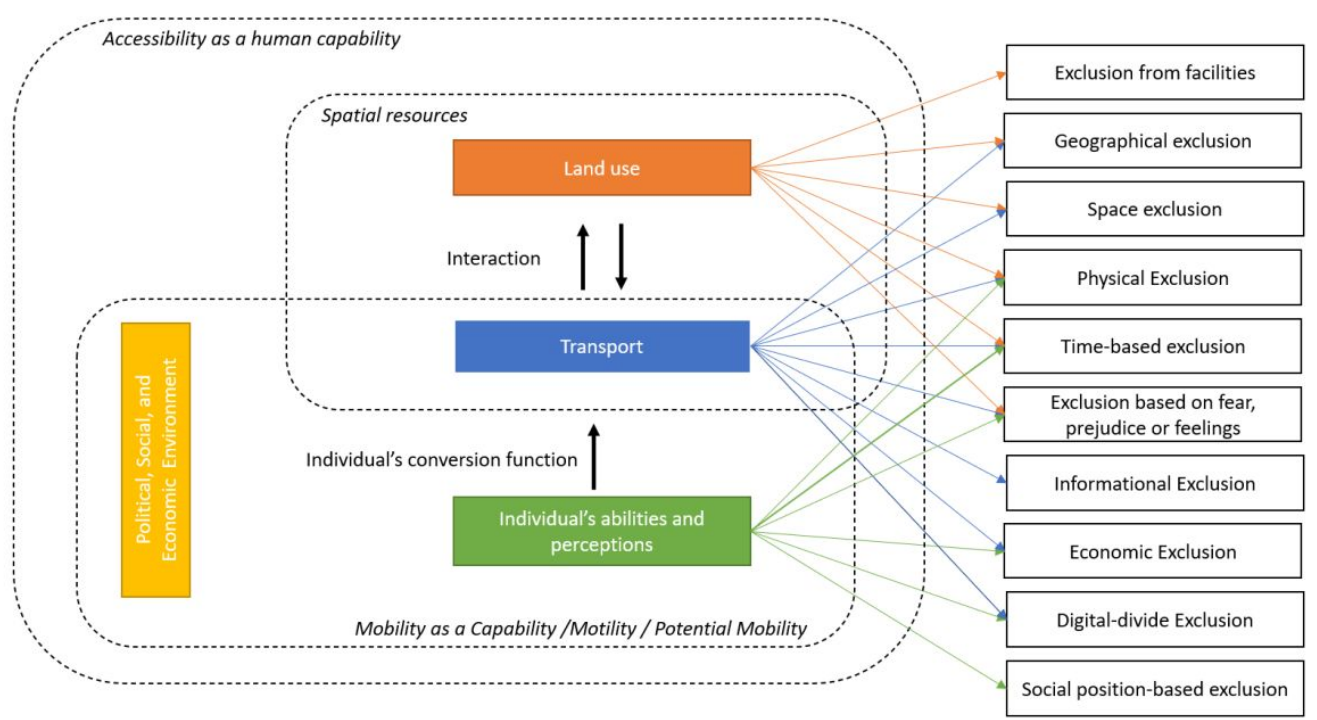

Source: Authors

Exclusion from facilities occurs due to the absence or distance to key opportunities such as employment, healthcare, schools, shops, or leisure services from where the individual lives. It may also occur when opportunities that can be accessed by public transport are not suitable for the individual. Increased diversity of activities offers opportunities to reduce the need for investment in services and employment outside the CBD, with subsequent impacts on distance, travel time, and the viability of modes such as public transport, walking, and cycling (Ma et al., 2018). More diverse areas allow individuals to reach activities walking and avoid expenditure with private car ownership (Ma et al., 2018; van Wee \& Geurs, 2011).

Geographical exclusion occurs when a person's residence location prevents $\mathrm{him} /$ her from accessing transport services, or the transport system does not connect to the places that the person wants to access. People living in regions distant from CBD in monocentric cities or activities are more likely to be accessibility disadvantaged (Delbosc \& Currie, 2011; Guimarães et al., 2019; Jaramillo et al., 2012). The low urban density is 
at the heart of the problem (Currie, 2010; Marquet et al., 2017; Pyrialakou et al., 2016). In dispersed land-use patterns, where the predominant mode of transport is the bus, the physical layout of the roads may restrict the efficient provision of services (Currie, 2010). The transport network's spatial coverage and connectivity are also factors that limit individuals` capabilities set (Casas \& Delmelle, 2014; Church et al., 2000; Engels \& Liu, 2011; Md Kamruzzaman \& Hine, 2012; I Shergold \& Parkhurst, 2012). Also, the emergence of new mobility services may cause a lock-out of places (ex: sparsely populated and remote areas) where these services cannot be accessed due to nonoperability (Groth, 2019; Lucas, 2019). Other elements of the built environment, such as connectivity of streets and sidewalks, sidewalks, and bicycle paths infrastructure, may influence the ease of access (Guimarães et al., 2019; Ma et al., 2018; Oviedo \& Sabogal, 2020).

While in developing countries, the lack of transportation and local activities force populations to travel long distances on foot (Lucas, 2011; Ureta, 2008), in developed countries, the effect is "forced car ownership" (Currie et al., 2010; Mattioli, 2014). Excessive dependence on walking as the primary means of transport can limit participation in other essential activities. Similarly, the economic stress caused by "forced car ownership" can lead to transport poverty and limit the number of trips to key opportunities. The lack of spatial resources is not equally or randomly distributed throughout society but follows well-defined patterns of structural social inequality (Bocarejo \& Oviedo, 2012; Jaramillo et al., 2012; Lucas, 2011; Ureta, 2008; Xiao et al., 2018). The locations with the worst levels of spatial resources are also those with the worst socioeconomic conditions (Jaramillo et al., 2012; Xiao et al., 2018).

Space exclusion occurs when security or space management of some public and private spaces discourages certain groups from using public and quasi-public transport 
spaces (e.g., first-class waiting rooms at stations) or certain areas (e.g., gated communities or areas of control militias). Certain types of surveillance and management of public transport spaces can weaken any sense of ownership amongst marginal groups (Church et al., 2000).

Physical and cognitive exclusion occurs when transport systems or the built environment may impose physical and cognitive barriers to individuals. Physical and cognitive difficulties in accessing transport and activities are widely cited in the literature as factors that can restrict an individual's capability set (Casas, 2007; Casas \& Delmelle, 2014; Currie et al., 2010; Delbosc \& Currie, 2011, Denmark, 1998; Engels \& Liu, 2011; Groth, 2019; Hine \& Mitchell, 2001; Hine \& Grieco, 2003; Kamruzzaman \& Hine, 2012; Lättman et al., 2016; Ma et al., 2018; Shergold \& Parkhurst, 2012; Social Exclusion Unit, 2003). Among the factors that may prevent individual's to access and use transport and activities are the inability to drive, design of transit vehicles, lack of adapted equipment for disabled people, saturated vehicle occupancy, inability to read timetable information, inadequate sidewalks. These are more frequently faced by the elderly, disabled, and illiterate. Difficulties include a deterioration in eyesight and hearing, poor coordination and slowed reactions, decreased and slower movements, and problems related to medication use (Denmark, 1998; Luiu \& Tight, 2021). They also present problems with balancing due to jerky stops and starts of vehicles, crowd movement, the physical impact, long walking distance to activities and transit stops, and lack of adapted seats and vehicles (Denmark, 1998). McCray \& Brais (2007) suggest that because women play multiple roles and, even nowadays, are primarily responsible for child care, they are also likely to face urban and vehicle design barriers when travelling accompanied by children or with baby carriages (McCray \& Brais, 2007). Regarding the built environment, poor pedestrian infrastructure may increase the risks of falls and stumbles for the elderly and 
physically disabled and, thus, limit accessibility (Ma et al., 2018; Shergold \& Parkhurst, 2012). The dependence on third parties of some disabled and older people limits the freedom of movement of these groups (Currie et al., 2010).

Time-based exclusion occurs when the low frequency of the transport system, lack of punctuality, or person's demands on time, such as work, child and elderly care duties, or other commitment may limit travel opportunities and imply the possibility to travel only at times when there is little or no transport services and activities available. The time people spend accessing, waiting for transport and travelling may limit their access to activities. It may be related to the frequency of service, network design, the number of transfers, operational speed, and distance to activities (Bocarejo \& Oviedo, 2012; Casas \& Delmelle, 2014; Delbosc \& Currie, 2012; Dharmowijoyo et al., 2020; Farber \& Páez, 2011; Guimarães et al., 2019; Lucas, 2011; Yigitcanlar et al., 2019). Excessive time spent to access activities may lead to time poverty, where travel is so time-consuming that there is little or no time left for other essential activities (Dharmowijoyo et al., 2020; Farber \& Páez, 2011). Currie et al. (2010) and Currie \& Delbosc (2010) identified that this phenomenon is related not only to socially disadvantaged but also advantaged highincome and economically active groups. Another issue to consider is the temporal variability of spatial resources (Fransen et al., 2015; Geurs \& van Wee, 2004; Lättman et al., 2016; Lucas, 2011; van Wee \& Geurs, 2011). The variation in the frequency of transport services and the working hours of facilities throughout the day and week can limit access during specific periods, such as weekends and off-peak periods (Kamruzzaman \& Hine, 2012).

Exclusion based on fear, prejudice, or feelings refers to the fear of crime and the perception of insecurity or prejudice that makes people avoid certain places (e.g., a particular neighbourhood, a bus stop). Also, aspects such as quality of the transport mode, 
safety during the journey and security to access to transport stations, cordiality of service providers influence the feeling about public transport and the perception of it as an option for travelling (Casas \& Delmelle, 2014; Guimarães et al., 2019; Lättman et al., 2016; Lucas, 2011). Feelings about built environment elements, such as neighbourhood aesthetics, public lighting, may influence the ease of access to activities (Guimarães et al., 2019; Ma et al., 2018). The TRSE literature acknowledges that are more likely to face this form of exclusion are the women and elderly. Women face concerns about personal security and harassment when accessing transit stops (Adeel et al., 2016; Casas \& Delmelle, 2014; Guimarães et al., 2019; Hine \& Grieco, 2003; McCray \& Brais, 2007). Overcrowding during travel is also a potential impediment, as their safety may be compromised by the risk of being sexually harassed by other passengers (Adeel et al., 2016; Casas \& Delmelle, 2014; Guimarães et al., 2019). The elderly frequently face the social disapproval that comes with slowing the movements of others during boarding and getting off transit vehicles (Denmark, 1998).

Informational exclusion refers to the lack of available information on public transport and destination options that prevent individuals from planning their journey and, therefore, limit its use (e.g. lack of travel information at transit stops, lack of information about the location of transit stops, and lack of information about interruptions of service) (Casas \& Delmelle, 2014; Lättman et al., 2016; Lucas, 2011; Yigitcanlar et al., 2019).

Economic exclusion occurs when the monetary costs of travel prevent people from travelling or restrict their access to destinations around their homes or mandatory activities. Most of the studies related to TRSE have identified poverty, low income, and unemployment as factors that prevent or limit individuals from accessing transport, thus compromising their participation in society (Bocarejo \& Oviedo, 2012; Casas, 2007; Currie et al., 2010; Denmark, 1998; Kamruzzaman \& Hine, 2012; Lucas, 2011; Ma et al., 
2018; Mattioli, 2014; Oviedo \& Sabogal, 2020; Social Exclusion Unit, 2003; Ureta, 2008; Walks, 2018). Low income and poverty have different effects on developed and developing countries. In developed countries, the impediment to using a particular transport mode can often be overcome by another less favourable but affordable, such as a car; even if it means spending a disproportionate percentage of the family budget on buying, owning, operating, and maintaining the vehicle (Currie et al., 2010; Mattioli, 2014; Pyrialakou et al., 2016; Walks, 2018). On the other hand, the impediment to travel and access activities in developing countries is often absolute. If one cannot travel by motorised transport, the journey will be made on foot or will not be made at all (Lucas, 2011; Ureta, 2008). The limited budget requires prioritisation of essential activities such as employment, education, and the maintenance of the house, and other essential activities to inclusion, such as leisure, visiting friends and relatives, are excluded (Lucas, 2011; Ureta, 2008).

Digital-divide exclusion occurs when the lack of digital connection or inability to use appropriate ICT may prevent individuals from using app-based transport systems. Difficulties in using appropriate ICT are critical elements limiting individuals`access to smart mobility (Groth, 2019). Vulnerable populations have considerably lower access to the "smart mobility ecosystem", including bank accounts, and remain disproportionately cash-dependent and face mobile data limitations (Golub et al., 2019).

Social position-based exclusion refers to the prevention from moving in public spaces due to censure, social control, or any other restriction based on one's social position (e.g., gender, race, nationality, age, ethnicity, caste, religion). A group likely to face this kind of exclusion is the migrants (Lauby, 2019; Ozkazanc, 2021). Because of a lack of language skills and illiteracy, migrants and refugees may face problems reading and understanding public transportation instructions and following the timetables (Ozkazanc, 
2021). Some authors also identified the group of young people as one that might face accessibility disadvantage because of its characteristics (Denmark, 1998; Hine \& Mitchell, 2001; Lauby, 2019; Ma et al., 2018; Social Exclusion Unit, 2003). There are concerns about the independence and safety of this group travelling unaccompanied by transit, cycling, or walking. Without transport or safe alternatives, young people may be denied the opportunities and services enjoyed by many of their peers (Denmark, 1998).

\section{The TRSE assessment}

Because TRSE is a complex phenomenon resulting from the interaction between several factors, its assessment is challenging. The appeal of using accessibility as a human capability in inclusive transport policies inevitably implies the need to develop and apply appropriate accessibility measures to assess the individual's capabilities. The notion of accessibility as a human capability is a more complex and multidimensional concept than those used in transportation studies (Pereira et al., 2017; Vecchio \& Martens, 2021). There are no accessibility measures that can fully capture all the nuances that influence an individual's capabilities. No matter how much of these nuances are considered in the accessibility measurement for the population, it is likely to give at best an approximation of people's capabilities.

The literature on accessibility measures emphasises the factors that shape accessibility but tends to ignore the relationship between these measures and the goals of accessibility (Martens, 2016a) and, consequently, social inclusion. However, the distributional outcomes of a given transportation policy will be considerably influenced by the accessibility measure chosen (Martens, 2012; Martens et al., 2012; Neutens et al., 2010). In this regard, the accessibility measures used to assess TRSE should be carefully chosen and connected with the social inclusion goals as well as the theoretical concerns 
discussed earlier in this work (Curl et al., 2011o; Geurs \& van Wee, 2004; Martens, 2012; Neutens et al., 2010).

Because there are no perfect accessibility measures that entirely comprise all the factors that influence an individual's capabilities, researchers should at least avoid existing measures that may theoretically conflict with the idea of accessibility as a human capability. Considering that the goal is to enable individuals' participation in the key activities of society, measures that do not account for all possible opportunities in which individuals can engage are not recommended. In this sense, infrastructure-based accessibility measurements, space-time measures that account for the available time to participate in activities, the volume of space-time prism, and potential path area can be discarded. Another problem of space-time measures is the impossibility to account for mandatory activities, such as employment, since the space-time prism is established based on the all spatio-temporal paths that an individual can take given its fixed activities (Miller, 1999).

Planning activities based on utility measures also may lead to a counterintuitive distribution of resources from a social perspective. This distorted distribution arises from the fact that a person can adjust his/her expectations according to his or her life situation (Martens, 2016b; Martens \& Golub, 2012; Sen, 2009). If utility is adopted as a benchmark for distributing transport resources, people with expensive preferences (see Martens \& Golub, 2012) would have a higher threshold of sufficient accessibility. In this scenario, advantaged people would have to receive more resources to obtain the same level of welfare as disadvantaged individuals.

Accessibility measures that adopt a maximisation strategy - they consider only the most advantageous activity for the individual - are not recommended to assess the TRSE risk (Martens \& Golub, 2012). This kind of measure fails to assess the set of viable 
opportunities for individual participation. The maximisation rule is restrictive and leaves little room for other decision rules that people may adopt when selecting activities (Neutens et al., 2010). Place-based measures focused on minimum distance or time, and some Burns-Miller space-time measures fall into this category.

Accessibility measures based on the actual observed behaviour of individuals also violate the idea of accessibility as a capability. People are not interested only in the actual functionings they attain but also in the range of functionings they could potentially achieve (capabilities) (Martens, 2016b; van Wee, 2016; van Wee \& Geurs, 2011). Activity-space and gravity measures with a decay function with parameters calibrated using observed travel data replicate biases (Handy \& Niemeier, 1997) and compromise identifying opportunities individuals could potentially access. Such measures are problematic as they suggest that individuals can access only activities within a distance or area that they access daily. It may suggest that an individual's capabilities are smaller than they actually are. For example, a person who carries out all his/her daily errands in places close to their residence because he/she lives in a place well served by facilities but can access and participate in activities much further away from their home.

A better alternative to calibrate and define activity-space and gravity measures using decay function is basing on the individual's cognitive feasible opportunities set (Kwan \& Hong, 1998). Many studies assume that a feasible set of opportunities is so small that the alternatives outside the distance or time threshold are not relevant to the individual. On the other hand, other studies assume that the feasible opportunity set is so vast that many of the alternatives contained therein are not perceived as possible to be accessed by the individual. In this sense, two aspects are essential in this calibration process: spatial knowledge or familiarity with various city areas and preference or aversion for specific locations. 
Although we should focus the accessibility analysis on the potential of what people can achieve (capabilities), the measurement of functionings (actual travel behaviour and activity participation) may be a good way to understand the appropriateness of accessibility measures to assess TRSE. We are not interested in the trips distances for the definition of decay function parameters or the size of activity space, but rather in the quantity and quality of the trips and activities in which one participated. It is expected that higher levels of accessibility (capabilities) are related to participation in more and/or better activities (functionings). If we test this relationship at the individual level, some individuals are likely to have high capabilities and not undertake trips and participate in activities because of their own choice. However, if we conduct an aggregated analysis of the whole population or group of individuals, this relationship must be valid. In this sense, a good accessibility measure must be, at least in part, related to the quantity and quality of the trips and activities. Otherwise, they will not be adequate to assess TRSE and may generate misleading results.

Some studies that examined the relationship between activity participation and travel behaviour with accessibility found that a positive relationship exists (Allen \& Farber, 2020; Fransen et al., 2018; Koenig, 1980; Thill \& Kim, 2005), while other studies found that this relationship was weak or not statistically significant (Dalvi \& Martin, 1976; Hanson \& Schwab, 1987; Kitamura et al., 2001). This lack of agreement in the literature may suggest that not every accessibility measure reflects the individual's capabilities and, therefore, not every measure is appropriate to assess the risk of TRSE. Alternatively, it may also suggest that accessibility measure choice must vary according to the context of analysis.

In this sense, the aggregated analysis between the relationship of accessibility measure and travel behaviour and activity participation may help select a measure that 
really depicts individuals`capability set. Also, an aggregated accessibility analysis may be helpful to identify TRSE cases due to spatial resources issues, such as poor transport systems or lack of activities. However, this kind of analysis may provide little insight into the individual's conversion function limitations. Such a deep understanding can only be achieved through an approach that starts from the individual as the unit of analysis. TRSE and the accessibility as human capability is fundamentally an individual notion and not always spatially clustered (Hine \& Grieco, 2003).

\section{Discussion and Conclusions}

Framing accessibility in the CA approach removes the policy focus on resource distribution. Accessibility as a human capability recognises the diversity of individuals' needs and preferences and their respective capabilities to convert spatial resources into results they value. Such conceptualisation provides the basis for a pragmatic approach of CA in inclusive transport planning. By sharing the sufficientarianist ideals, the notion of accessibility as a human capability combines accessibility needs with the idea of social rights - what Farrington (2007) called 'accessibility rights' - to the extent that a minimum level of accessibility is required to meet the basic needs of individuals. In this sense, public policies aimed at tackling TRSE should be founded on the concept of accessibility as a human capability, with strong sufficientarianism principles to prioritise and ensure a minimal level of capabilities for those in accessibility poverty. Adopting minimum accessibility requirements in practice would facilitate the implementation of normative criteria that can guarantee minimum accessibility standards for the entire population, preventing people from being denied to participate in society (Arranz-López et al., 2019). Furthermore, accessibility thresholds can provide policymakers with an understanding of 
how much accessibility is needed to meet the fundamental needs of the greatest number of people.

Nevertheless, there are some concerns related to the minimum level of accessibility. Should this level be a universal or relative concept? Should this be derived from our creation of value concerning what we as a society, academia, or policymakers see as just or even appropriate? Or is it a universal concept that is independent of our vision as a society? What types of activities should have a minimum level of access? Below what threshold does it imply a problem that legitimises or suggests the need for policy interventions (Farrington, 2007; Lucas et al., 2016; van Wee \& Geurs, 2011)? The definition of what a "normal level" of accessibility is and when the accessibility is below this threshold remains a practical and philosophical issue in TRSE literature and deserves further research (Arranz-López et al., 2019; Lucas, 2012; Lucas et al., 2016; Pereira et al., 2017; Pucci et al., 2019; van der Veen et al., 2020).

We advocate that the idea of a sufficient level of accessibility should be globallocal (Farrington \& Farrington, 2005). The concept abstracts particular circumstances; that is, all societies need a minimum level of accessibility, but its achievement will depend on specific local requirements. The relevance of activities will vary according to the political, economic, and social norms in that society and, therefore, participating in society will differ from society to society. Its definition is an explicitly normative process and demands a political decision taken through a genuine political and democratic process. Farrington \& Farrington (2005) highlight that relativism, in this case, is inevitable and enriches the concept of accessibility since it recognises the different ways in which values can impact spatially and culturally accessibility needs in society. By making this choice explicit and a significant part of the process, the definition of the 
minimum level of accessibility can be made transparent instead of being hidden in technical assumptions (van der Veen et al., 2020).

We proposed a framework that relates the notion of accessibility as a human capability and its related terms with ten TRSE dimensions. We suggest that accessibility as a human capability works as a reinforcing cycle. Individuals`capabilities set influences their well-being, and the functionings achieved, and well-being attained from them improve their individual conversion function and, consequently, their capabilities. The proposed framework allows consideration of how each individual may be prevented from travelling and accessing valued opportunities and how this may lead to each form of TRSE can take. Based on the past work, we suggest ten different dimensions of TRSE that individuals may experience. Although most categories have already been defined in the literature, we contribute to this framework by expanding their scope and proposing a new dimension: the digital divide exclusion.

The concept of accessibility as a human capability is more complex and multifaceted than those applied in transportation research. Since there are no accessibility measures that can fully capture an individual's capabilities, researchers will need to use measures that represent the best proxies currently available and do not violate the theoretical aspects of the idea of accessibility as a human capability. In this sense, many categories of accessibility measures were discarded, for example, those based on utility, maximisation strategies, calibrated and defined based on observed travel behaviour, and those that do not account for all possible opportunities in which individuals can engage. We suggest that an alternative for the definition and calibration process of activity space and gravity-based measures is to based on the cognitive feasible opportunity set. However, the measures will need to be individually specified. 
Although we are interested in what people can potentially achieve, we suggested that measuring what they actually do (actual travel behaviour and activity participation) may be a good way to understand which accessibility measures are more appropriate to assess TRSE. It is expected that higher levels of capabilities are related to higher levels of activity participation, and accessibility measures that fail to establish a valid relationship between those are not appropriate to assess TRSE. The literature that empirically assessed the relationship between accessibility and trip generation and activity participation has not yet reached a consensus on which accessibility measures are more appropriate to assess the risk of TRSE. It may suggest that not every accessibility measure reflects the individual's capabilities and that the choice of accessibility measure is likely to vary according to the analysis context.

In this sense, we recommend that planners conduct an aggregated analysis to check if the accessibility measure chosen is associated with more and/or better travel and activity participation. Conducting this analysis is important to avoid misleading results such as overestimate the impact of policy intervention in social exclusion reduction. The aggregated analysis may also be helpful to identify TRSE cases due to spatial resources issues, such as regions with poor transport systems or lack of activities. However, to have a deep understanding of individuals ' conversion function limitations, it is necessary to conduct a bottom-up analysis starting from the individual as the unit of analysis.

Finally, most of the TRSE research fails to differentiate between the causal factors behind TRSE and its social outcomes. Many of the TRSE factors are both the cause and result of TRSE. None of the empirical studies reviewed for this paper set out to establish causal inference between accessibility and level of participation. The vast majority of the papers adopted a correlational research design based on observational data, which is likely to be problematic due to endogeneity issues, such as omitted variables and 
simultaneity biases. In this sense, more empirical studies that evaluate the causal link between different accessibility measures and activity participation levels are highly desired to develop more successful inclusive transport policies.

\section{Disclosure statement}

No potential conflict of interest was reported by the authors.

\section{References}

Adeel, M., Yeh, A. G. O., \& Zhang, F. (2016). Transportation disadvantage and activity participation in the cities of Rawalpindi and Islamabad, Pakistan. Transport Policy, 47, 1-12. https://doi.org/10.1016/j.tranpol.2015.12.001

Allen, J., \& Farber, S. (2020). Planning transport for social inclusion: An accessibilityactivity participation approach. Transportation Research Part D: Transport and Environment, 78. https://doi.org/10.1016/j.trd.2019.102212

Arranz-López, A., Soria-Lara, J. A., \& Pueyo-Campos, Á. (2019). Social and spatial equity effects of non-motorised accessibility to retail. Cities, 86(May 2018), 7182. https://doi.org/10.1016/j.cities.2018.12.012

Bantis, T., \& Haworth, J. (2020). Assessing transport related social exclusion using a capabilities approach to accessibility framework: A dynamic Bayesian network approach. Journal of Transport Geography, 84(January), 102673. https://doi.org/10.1016/j.jtrangeo.2020.102673

Benevenuto, R., \& Caulfield, B. (2019). Poverty and transport in the global south: An overview. Transport Policy, 79(April), 115-124. https://doi.org/10.1016/j.tranpol.2019.04.018

Beyazit, E. (2011). Evaluating social justice in transport: Lessons to be learned from the capability approach. Transport Reviews, 31(1), 117-134. https://doi.org/10.1080/01441647.2010.504900 
Bocarejo S., J. P., \& Oviedo H., D. R. (2012). Transport accessibility and social inequities: a tool for identification of mobility needs and evaluation of transport investments. Journal of Transport Geography, 24, 142-154. https://doi.org/10.1016/j.jtrangeo.2011.12.004

Burchardt, T., Le Grand, J., \& Piachaud, D. (1999). Social exclusion in Britain 19911995. Social Policy and Administration, 33(3), 227-244. https://doi.org/10.1111/1467-9515.00148

Cao, M., \& Hickman, R. (2019a). Understanding travel and differential capabilities and functionings in Beijing. Transport Policy, 83, 46-56.

Casas, I. (2007). Social exclusion and the disabled: An accessibility approach. Professional Geographer, 59(4), 463-477. https://doi.org/10.1111/j.14679272.2007.00635.x

Casas, I., \& Delmelle, E. C. (2014). Identifying dimensions of exclusion from a BRT system in a developing country: A content analysis approach. Journal of Transport Geography, 39, 228-237. https://doi.org/10.1016/j.jtrangeo.2014.07.013

Cass, N., Shove, E., \& Urry, J. (2005). Social exclusion, mobility and access. Sociological Review, 53(3), 539-555. https://doi.org/10.1111/j.1467954X.2005.00565.X

Church, A., Frost, M., \& Sullivan, K. (2000). Transport and social exclusion in London. Transport Policy, 7(3), 195-205. https://doi.org/10.1016/S0967070X(00)00024-X

Curl, A., Nelson, J. D., \& Anable, J. (2011). Does accessibility planning address what matters? A review of current practice and practitioner perspectives. Research in Transportation Business and Management, 2, 3-11. https://doi.org/10.1016/j.rtbm.2011.07.001

Currie, G. (2010). Quantifying spatial gaps in public transport supply based on social needs. Journal of Transport Geography, 18(1), 31-41. https://doi.org/10.1016/j.jtrangeo.2008.12.002

Currie, G., \& Delbosc, A. (2010). Modelling the social and psychological impacts of transport disadvantage. Transportation, 37(6), 953-966. https://doi.org/10.1007/s11116-010-9280-2

Currie, G., Richardson, T., Smyth, P., Vella-Brodrick, D., Hine, J., Lucas, K., Stanley, J., Morris, J., Kinnear, R., \& Stanley, J. (2010). Investigating links between 
transport disadvantage, social exclusion and well-being in Melbourne - Updated results. Research in Transportation Economics, 29(1), 287-295.

https://doi.org/10.1016/j.retrec.2010.07.036

Dalvi, M. Q., \& Martin, K. M. (1976). The measurement of accessibility: Some preliminary results. Transportation, 5(1), 17-42. https://doi.org/10.1007/BF00165245

Delbosc, A., \& Currie, G. (2011). Transport problems that matter - social and psychological links to transport disadvantage. Journal of Transport Geography, 19(1), 170-178. https://doi.org/10.1016/j.jtrangeo.2010.01.003

Delbosc, A., \& Currie, G. (2012). Choice and disadvantage in low-car ownership households. Transport Policy, 23, 8-14. https://doi.org/10.1016/j.tranpol.2012.06.006

Denmark, D. (1998). The Outsiders: Planning and Transport Disadvantage. Journal of Planning Education and Research, 17, 231-245.

Dharmowijoyo, D. B. E., Susilo, Y. O., \& Syabri, I. (2020). Time use and spatial influence on transport-related social exclusion, and mental and social health. Travel Behaviour and Society, 21(April), 24-36. https://doi.org/10.1016/j.tbs.2020.05.006

Durand, A., Zijlstra, T., van Oort, N., Hoogendoorn-Lanser, S., \& Hoogendoorn, S. (2021). Access denied? Digital inequality in transport services. Transport Reviews, O(0), 1-26. https://doi.org/10.1080/01441647.2021.1923584

Engels, B., \& Liu, G. J. (2011). Social exclusion, location and transport disadvantage amongst non-driving seniors in a Melbourne municipality, Australia. Journal of Transport Geography, 19(4), 984-996. https://doi.org/10.1016/j.jtrangeo.2011.03.007

Farber, S., \& Páez, A. (2011). Running to stay in place: the time-use implications of automobile oriented land-use and travel. Journal of Transport Geography, 19(4), 782-793. https://doi.org/10.1016/j.jtrangeo.2010.09.008

Farrington, J., \& Farrington, C. (2005). Rural accessibility, social inclusion and social justice: towards conceptualisation. Journal of Transport Geography, 13(1), 112. https://doi.org/10.1016/j.jtrangeo.2004.10.002

Farrington, J. (2007). The new narrative of accessibility: its potential contribution to discourses in (transport) geography. Journal of Transport Geography, 15(5), 319-330. https://doi.org/10.1016/j.jtrangeo.2006.11.007 
Flamm, M., \& Kaufmann, V. (2006). Operationalising the concept of motility: A qualitative study. Mobilities, 1(2), 167-189. https://doi.org/10.1080/17450100600726563

Fransen, K, Farber, S., Deruyter, G., \& De Maeyer, P. (2018). A spatio-temporal accessibility measure for modelling activity participation in discretionary activities. Travel Behaviour and Society, 10, 10-20. https://doi.org/10.1016/j.tbs.2017.09.002

Fransen, K., Neutens, T., Farber, S., De Maeyer, P., Deruyter, G., \& Witlox, F. (2015). Identifying public transport gaps using time-dependent accessibility levels. Journal of Transport Geography, 48, 176-187. https://doi.org/10.1016/j.jtrangeo.2015.09.008

Geurs, K. T., \& van Wee, B. (2004). Accessibility evaluation of land-use and transport strategies: Review and research directions. Journal of Transport Geography, 12(2), 127-140. https://doi.org/10.1016/j.jtrangeo.2003.10.005

Golub, A., Satterfield, V., Serritella, M., Singh, J., \& Phillips, S. (2019). Assessing the barriers to equity in smart mobility systems: A case study of Portland, Oregon. Case Studies on Transport Policy, 7(4), 689-697. https://doi.org/10.1016/j.cstp.2019.10.002

Gray, D., Shaw, J., \& Farrington, J. (2006). Community transport, social capital and social exclusion in rural areas. Area, 38(1), 89-98. https://doi.org/10.1111/j.1475-4762.2006.00662.x

Groth, S. (2019). Multimodal divide: Reproduction of transport poverty in smart mobility trends. Transportation Research Part A: Policy and Practice, 125(May), 56-71. https://doi.org/10.1016/j.tra.2019.04.018

Guimarães, T., Lucas, K., \& Timms, P. (2019). Understanding how low-income communities gain access to healthcare services: A qualitative study in São Paulo, Brazil. Journal of Transport and Health, 15(July), 100658. https://doi.org/10.1016/j.jth.2019.100658

Hananel, R., \& Berechman, J. (2016). Justice and transportation decision-making: The capabilities approach. Transport Policy, 49, 78-85. https://doi.org/10.1016/j.tranpol.2016.04.005

Handy, S., \& Niemeier, D. (1997). Measuring Accessibility: An Exploration of Issues and Alternatives. Environment and Planning A: Economy and Space, 29(7), 1175-1194. https://doi.org/10.1068/a291175 
Hansen, W. G. (1959). How Accessibility Shapes Land Use. Journal of the American Planning Association, 25(2), 73-76. https://doi.org/10.1080/01944365908978307

Hanson, S., \& Schwab, M. (1987). Accessibility and intraurban travel. Environment \& Planning A, 19(6), 735-748. https://doi.org/10.1068/a190735

Hickman, R., Cao, M., Lira, B. M., Fillone, A., \& Biona, J. B. (2017). Understanding capabilities, functionings and travel in high and low income neighbourhoods in manila. Social Inclusion, 5(4), 161-174. https://doi.org/10.17645/si.v5i4.1083

Higgs, G., \& White, S. (2000). Alternatives to census-based indicators of social disadvantage in rural communities. Progress in Planning, 53(1), 1-81. https://doi.org/10.1016/S0305-9006(99)00021-5

Hine, J., \& Mitchell, F. (2001). Better for everyone? Travel experiences and transport exclusion. Urban Studies, 38(2), 319-332. https://doi.org/10.1080/00420980020018619

Hine, J., \& Grieco, M. (2003). Scatters and clusters in time and space: Implications for delivering integrated and inclusive transport. Transport Policy, 10(4), 299-306. https://doi.org/10.1016/S0967-070X(03)00055-6

Hodgson, F. C., \& Turner, J. (2003). Participation not consumption: The need for new participatory practices to address transport and social exclusion. Transport Policy, 10(4), 265-272. https://doi.org/10.1016/j.tranpol.2003.08.001

Jaramillo, C., Lizárraga, C., \& Grindlay, A. L. (2012). Spatial disparity in transport social needs and public transport provision in Santiago de Cali (Colombia). Journal of Transport Geography, 24, 340-357. https://doi.org/10.1016/j.jtrangeo.2012.04.014

Jeekel, J. F., \& Martens, C. J. C. M. (2017). Equity in transport: Learning from the policy domains of housing, health care and education. European Transport Research Review, 9(4), 1-13. https://doi.org/10.1007/s12544-017-0269-1

Kamruzzaman, Md, \& Hine, J. (2012). Analysis of rural activity spaces and transport disadvantage using a multi-method approach. Transport Policy, 19(1), 105-120. https://doi.org/10.1016/j.tranpol.2011.09.007

Kamruzzaman, Md, Yigitcanlar, T., Yang, J., \& Mohamed, M. A. (2016). Measures of transport-related social exclusion: A critical review of the literature.

Sustainability (Switzerland), 8(7), 6-11. https://doi.org/10.3390/su8070696

Kaufmann, V. (2002). Re-thinking mobility contemporary sociology. Ashgate. 
Kenyon, S., Lyons, G., \& Rafferty, J. (2002). Transport and social exclusion: Investigating the possibility of promoting inclusion through virtual mobility. Journal of Transport Geography, 10(3), 207-219. https://doi.org/10.1016/S0966-6923(02)00012-1

Kitamura, R., Akiyama, T., Yamamoto, T., \& Golob, T. F. (2001). Accessibility in a metropolis: Toward a better understanding of land use and travel. Transportation Research Record, 1780, 64-75. https://doi.org/10.3141/1780-08

Koenig, J. G. (1980). Indicators of urban accessibility: Theory and application. Transportation, 9(2), 145-172. https://doi.org/10.1007/BF00167128

Kwan, M.-P., \& Hong, X.-D. (1998). Network-based constraints-oriented choice set formation using GIS. Geographical Systems, 5, 139-162.

Lättman, K., Friman, M., \& Olsson, L. E. (2016). Perceived accessibility of public transport as a potential indicator of social inclusion. Social Inclusion, 4(3), 3645. https://doi.org/10.17645/si.v4i3.481

Lauby, F. (2019). Transportation and immigrant political incorporation. Journal of Ethnic and Migration Studies, 0(0), 1-18. https://doi.org/10.1080/1369183X.2019.1635003

Levitas, R. (2005). The inclusive society?: Social exclusion and new labour, second edition. In The Inclusive Society?: Social Exclusion and New Labour, Second Edition. https://doi.org/10.1057/9780230511552

Lira, B. M. (2017). Measuring Central Human Capabilities in Transport As a Complementary Method for Appraising Transport Projects in the Context of Santiago De Chile. Journal of Transport \& Health, 5, S109-S110. https://doi.org/10.1016/j.jth.2017.05.271

Lucas, K. (2006). Providing transport for social inclusion within a framework for environmental justice in the UK. Transportation Research Part A: Policy and Practice, 40(10), 801-809. https://doi.org/10.1016/j.tra.2005.12.005

Lucas, K. (2011). Making the connections between transport disadvantage and the social exclusion of low income populations in the Tshwane Region of South Africa. Journal of Transport Geography, 19(6), 1320-1334. https://doi.org/10.1016/j.jtrangeo.2011.02.007

Lucas, K. (2012). Transport and social exclusion: Where are we now? Transport Policy, 20, 105-113. https://doi.org/10.1016/j.tranpol.2012.01.013 
Lucas, K. (2019). A new evolution for transport-related social exclusion research? Journal of Transport Geography, 81(September), 102529. https://doi.org/10.1016/j.jtrangeo.2019.102529

Lucas, K., van Wee, B., \& Maat, K. (2016). A method to evaluate equitable accessibility: combining ethical theories and accessibility-based approaches. Transportation, 43(3), 473-490. https://doi.org/10.1007/s11116-015-9585-2

Luiu, C., \& Tight, M. (2021). Travel difficulties and barriers during later life: Evidence from the National Travel Survey in England. Journal of Transport Geography, 91(December 2020), 102973. https://doi.org/10.1016/j.jtrangeo.2021.102973

Ma, L., Kent, J. L., \& Mulley, C. (2018). Transport disadvantage, social exclusion, and subjective well-being: The role of the neighborhood environment-evidence from Sydney, Australia. Journal of Transport and Land Use, 11(1), 31-47. https://doi.org/10.5198/jtlu.2018.1008

Marquet, O., Bedoya, V. R., \& Miralles-Guasch, C. (2017). Local accessibility inequalities and willingness to walk in Latin-American cities: Findings from Medellín, Colombia. International Journal of Sustainable Transportation, 11(3), 186-196. https://doi.org/10.1080/15568318.2016.1230804

Martens, K. (2012). Justice in transport as justice in accessibility: Applying Walzer's "Spheres of Justice" to the transport sector. Transportation, 39(6), 1035-1053. https://doi.org/10.1007/s11116-012-9388-7

Martens, K. (2015). Accessibility and Potential Mobility as a Guide for Policy Action. Transportation Research Record: Journal of the Transportation Research Board, 2499(October 2015), 18-24. https://doi.org/10. 3141/2499-03

Martens, K. (2016a). Transport Justice. In Transport Justice: Designing fair transportation systems. Routledge. https://doi.org/10.4324/9781315746852

Martens, K. (2016b). Why Accessibility Measurement is Not Merely an Option, but an Absolute Necessity. Designing Accessibility Instruments, July, 37-51. https://doi.org/10.4324/9781315463612-4

Martens, K., \& Bastiaanssen, J. (2019). An index to measure accessibility poverty risk. In Measuring Transport Equity. https://doi.org/10.1016/B978-0-12-814818$1.00003-2$

Martens, K., \& Golub, A. (2012). A justice- theoretic exploration of accessibility measures. Accessibility Analysis and Transport Planning: Challenges for 
Europe and North America, July 2014, 195-210.

https://doi.org/10.4337/9781781000113.00020

Martens, K., Golub, A., \& Robinson, G. (2012). A justice-theoretic approach to the distribution of transportation benefits: Implications for transportation planning practice in the United States. Transportation Research Part A: Policy and Practice, 46(4), 684-695. https://doi.org/10.1016/j.tra.2012.01.004

Mattioli, G. (2014). Where Sustainable Transport and Social Exclusion Meet:

Households Without Cars and Car Dependence in Great Britain. Journal of Environmental Policy and Planning, 16(3), 379-400.

https://doi.org/10.1080/1523908X.2013.858592

Mattioli, G., Lucas, K., \& Marsden, G. (2018). Reprint of Transport poverty and fuel poverty in the UK: From analogy to comparison. Transport Policy, 65(February 2016), 114-125. https://doi.org/10.1016/j.tranpol.2018.02.019

McCray, T., \& Brais, N. (2007). Exploring the role of transportation in fostering social exclusion: The use of GIS to support qualitative data. Networks and Spatial Economics, 7(4), 397-412. https://doi.org/10.1007/s11067-007-9031-x

Meyer, L. H., \& Roser, D. (2009). Enough for the Future. In Intergenerational Justice (pp. 219-248). Oxford University Press. https://doi.org/10.1093/acprof:oso/9780199282951.003.0009

Miller, H. J. (1999). Measuring space-time accessibility benefits within transportation networks: Basic theory and computational procedures. Geographical Analysis, 31(2), 187-212. https://www.scopus.com/inward/record.uri?eid=2-s2.00032775876\&partnerID=40\&md5=eeb38fe24e881a5331dfb946dfda31af

Nahmias-Biran, B. H., Martens, K., \& Shiftan, Y. (2017). Integrating equity in transportation project assessment: a philosophical exploration and its practical implications. Transport Reviews, 37(2), 192-210. https://doi.org/10.1080/01441647.2017.1276604

Neutens, T., Schwanen, T., Witlox, F., \& de Maeyer, P. (2010). Equity of urban service delivery: A comparison of different accessibility measures. Environment and Planning A, 42(7), 1613-1635. https://doi.org/10.1068/a4230

Nussbaum, M. (2011). Creating capabilities: The human development approach. Belknap Press of Harvard University Press.

Nussbaum, M., \& Sen, A. (Eds.). (1993). The Quality of Life. Oxford University Press. https://doi.org/10.1093/0198287976.001.0001 
Oviedo, D., \& Guzman, L. A. (2020). Revisiting accessibility in a context of sustainable transport: Capabilities and inequalities in Bogota. Sustainability (Switzerland), 12(11). https://doi.org/10.3390/su12114464

Oviedo, D., \& Sabogal, O. (2020). Unpacking the connections between transport and well-being in socially disadvantaged communities: Structural equations approach to low-income neighbourhoods in Nigeria. Journal of Transport and Health, 19(October 2019), 100966. https://doi.org/10.1016/j.jth.2020.100966

Ozkazanc, S. (2021). Transportation experiences of Syrian refugees under the clampdown of poverty, social exclusion and spatial segregation. Cities, 112(May 2020), 103117. https://doi.org/10.1016/j.cities.2021.103117

Pereira, R. H. M., Schwanen, T., \& Banister, D. (2017). Distributive justice and equity in transportation. Transport Reviews, 37(2), 170-191. https://doi.org/10.1080/01441647.2016.1257660

Preston, J., \& Rajé, F. (2007). Accessibility, mobility and transport-related social exclusion. Journal of Transport Geography, 15(3), 151-160. https://doi.org/10.1016/j.jtrangeo.2006.05.002

Pucci, P., Vecchio, G., Bocchimuzzi, L., \& Lanza, G. (2019). Inequalities in job-related accessibility: Testing an evaluative approach and its policy relevance in Buenos Aires. Applied Geography, 107, 1-11. https://doi.org/10.1016/j.apgeog.2019.04.002

Pyrialakou, V. D., Gkritza, K., \& Fricker, J. D. (2016). Accessibility, mobility, and realized travel behavior: Assessing transport disadvantage from a policy perspective. Journal of Transport Geography, 51, 252-269. https://doi.org/10.1016/j.jtrangeo.2016.02.001

Rawls, J. (2009). A theory of Justice. Harvard University Press.

Ryan, J., Wretstrand, A., \& Schmidt, S. M. (2015). Exploring public transport as an element of older persons' mobility: A Capability Approach perspective. Journal of Transport Geography, 48, 105-114. https://doi.org/10.1016/j.jtrangeo.2015.08.016

Ryan, J., Wretstrand, A., \& Schmidt, S. M. (2019). Disparities in mobility among older people: Findings from a capability-based travel survey. Transport Policy, 79(February 2018), 177-192. https://doi.org/10.1016/j.tranpol.2019.04.016

Schwanen, T., Lucas, K., Akyelken, N., Cisternas Solsona, D., Carrasco, J. A., \& Neutens, T. (2015). Rethinking the links between social exclusion and transport 
disadvantage through the lens of social capital. Transportation Research Part A: Policy and Practice, 74, 123-135. https://doi.org/10.1016/j.tra.2015.02.012

Sen, A. (1985). Commodities and Capabilities. North Holland.

Sen, A. (1995). Inequality Reexamined. Oxford University Press. https://doi.org/10.1093/0198289286.001.0001

Sen, A. (2009). The idea of justice. Harvard University Press.

Shergold, I, \& Parkhurst, G. (2012). Transport-related social exclusion amongst older people in rural Southwest England and Wales. Journal of Rural Studies, 28(4), 412-421. https://doi.org/10.1016/j.jrurstud.2012.01.010

Social Exclusion Unit. (2003). Making the Connections: Final Report on Transport and Social Exclusion. https://doi.org/10.1680/muen.156.2.81.37660

Stanley, J., \& Vella-Brodrick, D. (2009). The usefulness of social exclusion to inform social policy in transport. Transport Policy, 16(3), 90-96. https://doi.org/10.1016/j.tranpol.2009.02.003

Thill, J. C., \& Kim, M. (2005). Trip making, induced travel demand, and accessibility. Journal of Geographical Systems, 7(2), 229-248. https://doi.org/10.1007/s10109-005-0158-3

United Nations. (2016). Leaving No One Behind - The Imperative of Inclusive Development (Vol. 148). https://www.refworld.org/docid/5840368e4.html

Ureta, S. (2008). To move or not to move? Social exclusion, accessibility and daily mobility among the low-income population in Santiago, Chile. Mobilities, 3(2), 269-289. https://doi.org/10.1080/17450100802095338

van der Veen, A. S., Annema, J. A., Martens, K., van Arem, B., \& Correia, G. H. de A. (2020). Operationalizing an indicator of sufficient accessibility - a case study for the city of Rotterdam. Case Studies on Transport Policy, 8(4), 1360-1370. https://doi.org/10.1016/j.cstp.2020.09.007

van Wee, B. (2016). Accessible accessibility research challenges. Journal of Transport Geography, 51, 9-16. https://doi.org/10.1016/j.jtrangeo.2015.10.018

van Wee, B., \& Geurs, K. (2011). Discussing equity and social exclusion in accessibility evaluations. European Journal of Transport and Infrastructure Research, 11(4), 350-367.

Vecchio, G., \& Martens, K. (2021). Accessibility and the Capabilities Approach: a review of the literature and proposal for conceptual advancements. Transport Reviews, O(0), 1-22. https://doi.org/10.1080/01441647.2021.1931551 
Walks, A. (2018). Driving the poor into debt? Automobile loans, transport disadvantage, and automobile dependence. Transport Policy, 65, 137-149. https://doi.org/10.1016/j.tranpol.2017.01.001

Xiao, R., Wang, G., \& Wang, M. (2018). Transportation Disadvantage and Neighborhood Sociodemographics: A Composite Indicator Approach to Examining Social Inequalities. Social Indicators Research, 137(1), 29-43. https://doi.org/10.1007/s11205-017-1616-2

Yigitcanlar, T., Mohamed, A., Kamruzzaman, M., \& Piracha, A. (2019). Understanding Transport-Related Social Exclusion: A Multidimensional Approach. Urban Policy and Research, 37(1), 97-110. https://doi.org/10.1080/08111146.2018.1533461 


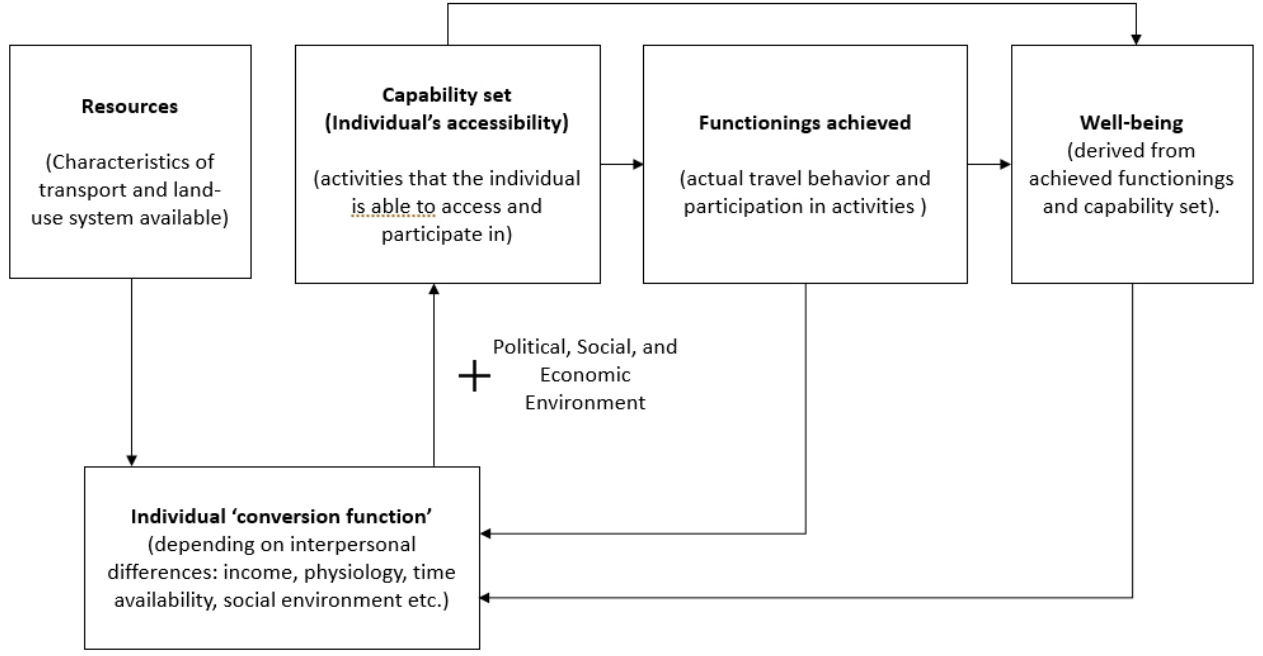

Figure 1: Accessibility as a Human Capability $554 \times 302 \mathrm{~mm}(47 \times 47 \mathrm{DPI})$ 


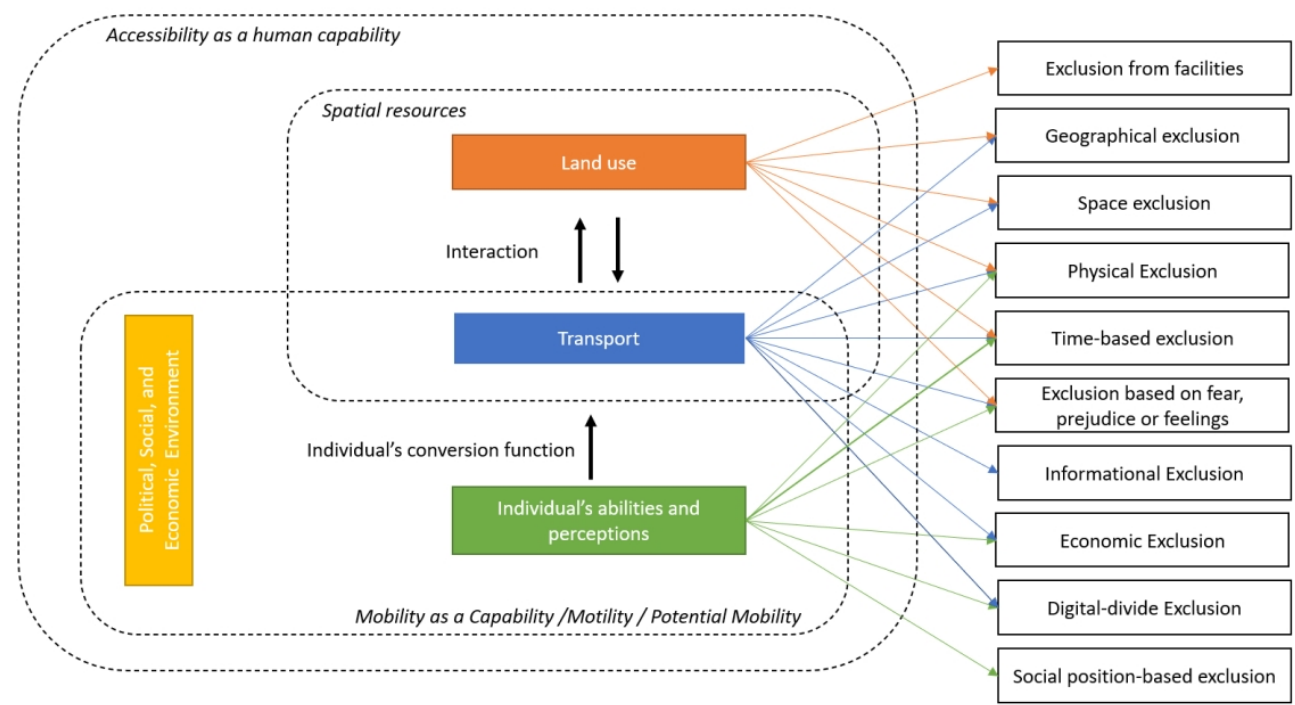

Figure 2: Relationship between accessibility as human capability components and TRSE dimensions $858 \times 480 \mathrm{~mm}(47 \times 47$ DPI $)$ 